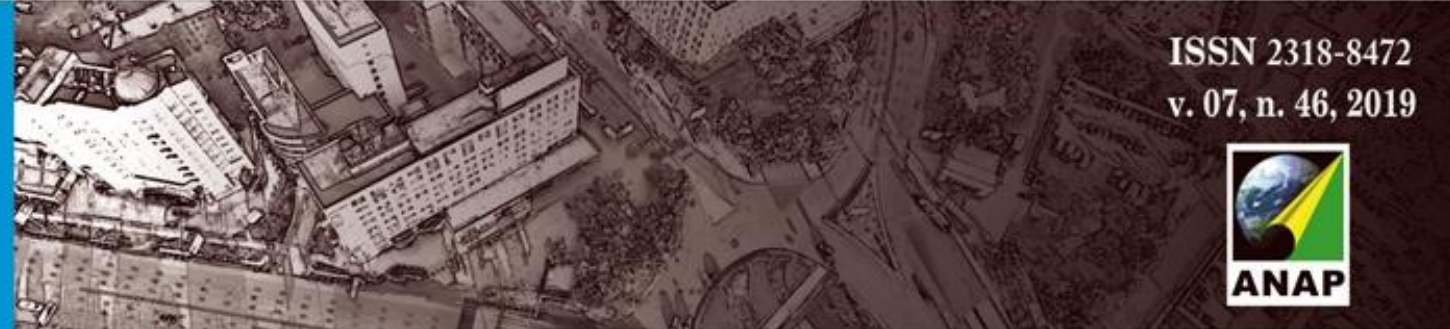

Revista Nacional de Gerenciamento de Cidades

\title{
Certificações de qualidade em usinas de cana-de-açúcar
}

Quality certifications in sugar cane mills

Certificaciones de calidad en usinas de caña de azúcar

\section{Maria José Floriano Ferracini}

Mestre em Ciências Ambientais pela Universidade Brasil, Fernandópolis, SP, Brasil coorcontabeisfama@hotmail.com

\section{Gisele Herbst Vazquez}

Professora Doutora, Universidade Brasil, Fernandópolis, SP, Brasil gisele.vazquez@universidadebrasil.edu.br 


\section{RESUMO}

Uma empresa para ser sustentável necessita primeiro ter a consciência de que seu processo de produção causa impactos ao meio ambiente. Posteriormente, deve procurar alternativas, como a implantação de políticas ambientais, projetos e certificações de acordo com o seu ramo de atividade. E por fim, ter a capacidade de medir adequadamente a sustentabilidade empresarial, considerando políticas mais específicas de acordo com as leis, mercado e meio ambiente, obtendo selos e demostrando que possui responsabilidade ambiental. O objetivo nesta pesquisa foi elaborar um levantamento referente as certificações de qualidade adotadas nos maiores grupos sucroenergéticos brasileiros, ou seja, os grupos Raízen, Odebrechet, Biosev, Guarani, São Martinho, Usaçucar, Alto Alegre e Coruripe. Concluiu-se que a qualidade é preocupação essencial no setor sucroenergético. A internacionalização, decorrente da globalização, fez com que as empresas focassem esforços para adquirir certificações que autentiquem e garantam a qualidade de seus produtos e a inserção em novos mercados. Vinte e uma certificações foram apresentadas: três relacionadas à sustentabilidade e ao gerenciamento ambiental, uma à gestão de qualidade na empresa, uma à saúde dos trabalhadores, três à segurança alimentar, duas a dietas de comunidades religiosas, três à segurança e à precisão dos laboratórios, um prêmio de agroenergia e meio ambiente, um selo de energia limpa, além de seis certificações para exportação de biocombustíveis para os EUA e União Europeia.

Palavras-chave: sustentabilidade, setor sucroenergético, selo ambiental

\section{ABSTRACT}

A company to be sustainable first needs to be aware that its production process affects the environment. Subsequently, it should look for alternatives, such as the implementation of environmental policies, projects and certifications according to its branch of activity. And finally, have the ability to measure appropriately business sustainability, considering more specific policies in accordance with laws, market and environment, obtaining stamps and proving that it has environmental responsibility. The objective of this research was to elaborate a survey about the quality certifications adopted in the largest Brazilian sugarcane groups, that is, the Raízen, Odebrechet, Biosev, Guarani, São Martinho, Usaçucar, Alto Alegre and Coruripe groups. It was concluded that quality is an essential concern in the Sugarcane sector. Internationalization, the result of globalization, has made companies focus efforts to acquire certifications that authenticate and guarantee the quality of their products and the insertion in new markets. Twenty one certifications were presented: three related to sustainability and environmental management, one to quality management in the company, one to workers' health, three to food safety, two to diets of religious communities, three to safety and the precision of laboratories, an award on agroenergy and the environment, a clean energy seal plus six certifications required for the export of biofuels to the US and the European Union.

Keywords: sustainability, sugarcane sector, environmental seal

\section{RESUMEN}

Una empresa para ser sostenible necesita primero tener la conciencia de que su proceso de producción causa impactos al medio ambiente. Posteriormente, debe buscar alternativas, como la implantación de políticas ambientales, proyectos y certificaciones de acuerdo con su rama de actividad. Y por último, tener la capacidad de medir adecuadamente la sostenibilidad empresarial, considerando políticas más específicas de acuerdo con leyes, mercado y medio ambiente, obteniendo sellos y demostrando que posee responsabilidad ambiental. El objetivo en esta investigación fue elaborar un dictamen referente a las certificaciones de calidad adoptadas en los mayores grupos sucroenergéticos brasileños, o sea, los grupos Raízen, Odebrechet, Biosev, Guaraní, São Martinho, Usaçucar, Alto Alegre y Coruripe. Se concluyó que la calidad es una preocupación esencial en el sector sucroenergético. La internacionalización, fruto de la globalización, ha hecho que las empresas se centraran en adquirir certificaciones que autentiquen y garanticen la calidad de sus productos y la inserción en nuevos mercados. Se han presentado veintiuno certificaciones: tres relacionadas a la sostenibilidad y gestión ambiental, una a la gestión de calidad en la empresa, una a la salud de los trabajadores, tres a la seguridad alimentaria, dos a dietas de comunidades religiosas, tres a la seguridad y a la precisión de los laboratorios, un premio relativo a la agroenergía y el medio ambiente, un sello de energía limpia además de seis certificaciones exigidas para la exportación de biocombustibles a Estados Unidos y la Unión Europea.

Palabras clave: sostenibilidad, sector sucroenergético, sello ambiental 


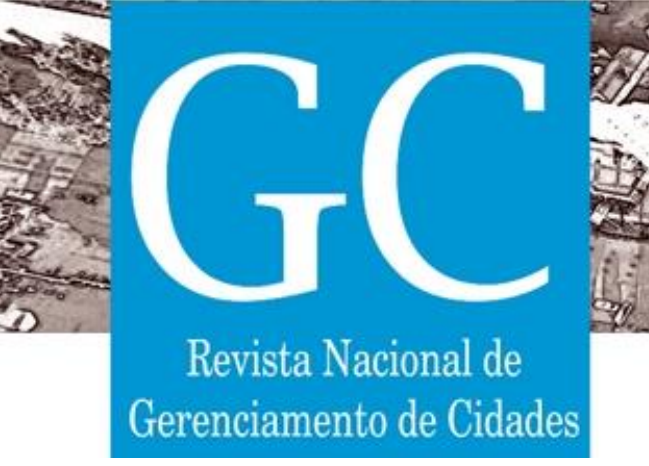

\section{INTRODUÇÃO}

Certificação é o conjunto de atividades desenvolvidas por organismo independente da relação comercial, com objetivo de atestar publicamente que determinado produto, processo ou serviço está em conformidade com os requisitos especificados (VICENTE, 2012).

As certificações de qualidade almejam garantir que, independentemente da localidade a qual o produto foi produzido, este segue padrões criteriosos, que o qualificam a ser consumido de forma a atender aos critérios de qualidade elencados nas normas regulamentadoras para as empresas competirem no mercado atual, podendo estender suas produções para fronteiras além da região nacional limítrofe.

A certificação pode ser implantada em qualquer empresa pública ou privada, em que obter essa certificação significa que a empresa atende os requisitos da qualidade. Os benefícios de implantar este sistema são, que, a empresa passa uma imagem segura para o cliente e para os colaboradores, além de, aumentar a produção e reduzir os custos.

Durante a Conferência das Nações Unidas sobre Meio Ambiente e Desenvolvimento, em 1992, o setor industrial percebeu que a preocupação com os recursos naturais e seu uso racional poderia proporcionar ganhos em um mercado cada vez mais competitivo e globalizado, surgindo assim, as normas ambientais voluntárias como resposta do setor produtivo frente às discussões e proposições quanto ao desenvolvimento sustentável, como por exemplo, as certificações "ISO" (International Standardization Organization).

Uma empresa ao implementar um sistema de gestão da qualidade poderá melhorar seus processos e a qualidade de seus produtos e serviços frente aos clientes, porém para que o resultado seja reconhecido, será necessário que outra empresa especializada em auditoria de gestão da qualidade faça esse serviço. Assim, obtém-se um certificado da qualidade, que irá depender da área onde a empresa atua, e também, das normas que regem esta área. Sendo assim, existem dois tipos de certificados válidos: o Certificado de Acreditação (que diz respeito a Laboratórios de Ensaio e Calibração e de Análises Clínicas) e de Certificação (baseado na norma ABNT NBR ISO 9001:2008, ABNT NBR ISO 14001 e etc).

Cabe aos órgãos reguladores, o papel de averiguar o sistema de certificação que cada empresa adota em seus processos, a fim de garantir que estão dentro dos padrões e especificações nacionais e internacionais (VICENTE, 2012), sendo, no Brasil, a Agência Brasileira de Normas Técnicas ( $A B N T$ ) o órgão regulador. O Sistema de Gestão de Qualidade estabelece um conjunto de requisitos que a organização deve apresentar no processo de fabricação de seus produtos, atendendo a satisfação e necessidade do cliente quanto aos requisitos estabelecidos pela ABNT, adquirindo assim, o selo de Qualidade ABNT NBR ISO 9001:2008 (BATALHA, 2012).

Com o intenso crescimento econômico das últimas décadas houve um agravamento dos problemas ambientais. Por essa razão foi criada em setembro de 1996 as normas ABNT NBR ISO 14000, por meio da liderança da ISO. A ABNT NBR ISO 14000 é um conjunto de normas 


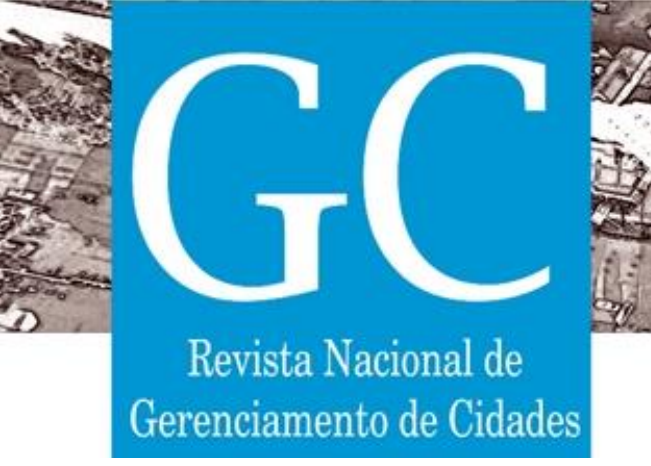

voluntárias para padronizar e criar um Sistema de Gestão Ambiental nas empresas. A série ABNT NBR ISO 14000 engloba seis grupos de normas, cada uma delas atendendo a um assunto específico da questão ambiental. Esses grupos são: Sistema de gestão ambiental (ABNT NBR ISO 14001), Sistema de auditorias ambientais (ABNT NBR ISO 14010, 14011 e 14012), Sistema de avaliação do desempenho ambiental (ABNT NBR ISO 14031), Sistema de rotulagem ambiental (ABNT NBR ISO 14020, 14021 e 14024), Aspectos ambientais em normas de produtos (ABNT NBR ISO15060) e Análise do ciclo de vida do produto (ABNT NBR ISO 14040) (SILVA, 2011).

Atualmente, a adesão a esse pacote e a outros existentes, funciona também como um impulsionador de vendas e de entrada em mercados mais exigentes, onde a ausência de respeito ambiental no processo produtivo se constitui em uma barreira para alguns produtos em importantes mercados consumidores.

O setor sucroenergético, devido ao uso expressivo dos recursos naturais e aos impactos significativos no meio ambiente, sofre maior pressão para adoção de legislações e certificações que minimizem estes impactos. Assim, as usinas estão mudando a visão para adoção de estratégias e readequação de técnicas nos processos de fabricação de etanol, açúcar e energia, para atender as exigências dos órgãos reguladores (RODRIGUES et al., 2014).

Existem uma gama extensa de certificações inerentes ao setor sucroenergético, as quais destaca-se Better Sugarcane Iniciative, Certificação mesa redonda biocombustíveis sustentáveis, Greeenergy Bioethanol Sustainability Programme, Protocolo agroambiental, Certificação de projetos de MDL, Environmental Protection Agency, International Sustainability and Carbon Certification, Roundtable on Sustainable Biofuels e Global Reporting Iniciative.

A Better Sugarcane Iniciative (Bonsucro), segundo Vicente (2012), é uma certificação global lançada em julho de 2011 que avalia a sustentabilidade dos produtos fabricados a partir da cana e é atualmente o modelo de certificação mais utilizado no Brasil, com 20 empresas sucroenergéticas e mais de 437 mil ha de cana avalizados, o que equivale a mais de $1,7 \%$ da cana cultivada no mundo. Destaca-se entre seus objetivos: a promoção da melhoria nos processos de produção da cana-de-açúcar por meio da definição de critérios, princípios, métodos e padrões concernentes ao desempenho do processo.

Quanto as demais certificações, Rodrigues et al. (2014) as conceituam da seguinte forma:

- Greenergy Bioethanol Sustainability Programme: atesta a produção de etanol anidro de forma mais sustentável e maximiza a redução de emissão de gases de efeito estufa;

- Protocolo Agroambiental: estimula ações de sustentabilidade no processo de produção do açúcar e bionergia;

- Certificação de Projetos de MDL: comprova redução da emissão de gases do efeito estufa;

- Environmental Protection Agency (EPA): autoriza a exportação do Etanol para países norte americanos;

- International Sustainability and Carbon Certification (ISCC): cita parâmetros de biomassa e bioenergia dentro dos paises membros da União-Europeia;

- Roundtable on Sustainable Biofuels (RSB): garante a sustentabilidade dos biocombustíveis; 


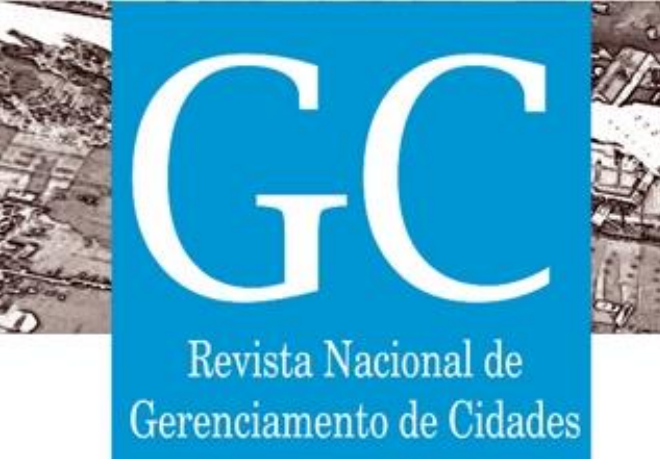

- Global Reporting Iniciative (GRI): realiza relatórios internacionais de sustentabilidade, visa indicadores das práticas, gestão e desempenho econômico, social e ambiental.

As empresas que optam por adotar e seguir as certificações exigidas pelos órgaos reguladores, demostram que se importam com os impactos que causam ao meio ambiente e que traçam estratégias de minimização dos mesmos.

\subsection{Objetivo}

O objetivo nesta pesquisa foi elaborar um levantamento referente as certificações de qualidade adotadas nos maiores grupos sucroenergéticos brasileiros, ou seja, os grupos Raízen, Odebrechet, Biosev, Guarani, São Martinho, Usaçucar, Alto Alegre e Coruripe.

\section{METODOLOGIA}

A partir de uma revisão bibliográfica como ponto primordial do estudo acadêmico por atribuir rigor científico (SEVERINO, 2007), foi desenvolvida esta pesquisa entre os meses de abril a julho de 2017. No que tange a delimitação de seu universo, foi realizado um levantamento dos oito maiores grupos atuais no setor sucroenergético, sendo estas: Raízen, Odebrechet, Biosev, Guarani, São Martinho, Usaçucar, Alto Alegre e Coruripe, todas de moagem de cana-de-açúcar e produtoras de açúcar e etanol e algumas de energia.

A pesquisa adotada foi a de campo fundamentalmente qualitativa, conceituada por Marconi e Lakatos (2005) como aquela que permite apresentar um diagnóstico da empresa, tendo como foco os relatórios de sustentabilidade compreendidos entre os anos de 2015-2016, a fim de dimensionar a importância do aspecto ambiental no direcionamento estratégico da empresa e seu engajamento em projetos de certificação ambiental.

Também foram realizadas consultas ao acervo digital e de mídias sociais dos oito grupos, além de entrevistas com algumas unidades, visto que nem todas foram receptivas, com o intuito de averiguar quais são as ações de garantia da qualidade ambiental proposta e/ou desenvolvidas por estes e que estão em pleno funcionamento.

\section{RESULTADOS E DISCUSSÃO}

Segundo o site InfoCana (2018), os oito maiores grupos brasileiros quanto a moagem, açúcar, etanol e energia comercializada nas safras de 2015/2016 estão apresentados nas Tabela 1. 
Tabela 1: Capacidade produtiva dos grupos sucroenergéticos conforme ranking da safra 2015/16 no Brasil

\begin{tabular}{|c|c|c|c|c|c|}
\hline & Grupos & $\begin{array}{l}\text { Moagem } \\
\text { (t) }\end{array}$ & $\begin{array}{l}\text { Açúcar } \\
\text { (t) }\end{array}$ & $\begin{array}{c}\text { Etanol } \\
\left(\mathrm{m}^{3}\right)\end{array}$ & $\begin{array}{c}\text { Energia } \\
\text { Comercializada } \\
\text { (MW) }\end{array}$ \\
\hline 1 & Raizen & $1^{\circ}-62.700 .000,0$ & $1^{\circ}-4.177 .700,0$ & $1^{\circ}-2.073 .900,0$ & $2^{\circ}-2.870 .000,0$ \\
\hline 2 & Odebrechet & $3^{\circ}-29.292 .632,0$ & $15^{\circ}-455.309,0$ & $2^{\circ}-2.041 .985,0$ & $1^{\circ}-2.972 .685,0$ \\
\hline 3 & Biosev & $2^{\circ}-30.959 .000,0$ & $2^{\circ}-1.705 .000,0$ & $3^{\circ}-1.239 .000,0$ & $2^{\circ}-2.870 .000,0$ \\
\hline 4 & Guarani & $279^{\circ}-N R P$ & NRP & NRP & NRP \\
\hline 5 & São Martinho & $4^{\circ}-22.381 .359,69$ & $5^{\circ}-1.229 .700,05$ & $4^{\circ}-943.766,52$ & $5^{\circ}-907.780,07$ \\
\hline 6 & Usaçucar & $7^{\circ}-17.968 .476,88$ & $3^{\circ}-1.689 .464,0$ & $12^{\circ}-445.946,0$ & $12^{\circ}-380.000,0$ \\
\hline 7 & Alto Alegre & $56^{\circ}-2.718 .455,0$ & $20^{\circ}-240.020,0$ & $121^{\circ}-69.107,0$ & NRP \\
\hline 8 & Coruripe & $38^{\circ}-3.032 .565,18$ & $16^{\circ}-262.201,0$ & $117^{\circ}-70.348,59$ & $59^{\circ}-20.522,0$ \\
\hline
\end{tabular}

NRP- Não Respondeu a Pesquisa

Fonte: Adaptado de InfoCana, 2018

Complementando a Tabela 1, é apresentado no Quadro 1 um panorama geral de oito grandes grupos sucroenergéticos segundo os seus relatórios de sustentabilidade dos anos de $2015 \mathrm{e}$ 2016, quantificando, porém, a produção de açúcar, etanol e cogeração de energia de forma discrepante da Tabela 1, que foi baseada em dados do InfoCana.

Quadro 1: Panorama dos grupos sucroenergéticos analisados, 2015/16

\begin{tabular}{|l|c|c|c|c|c|c|c|c|}
\hline Indicador & Raízen & Odebrecht & Biosev & Guarani & $\begin{array}{c}\text { São } \\
\text { Martinho }\end{array}$ & Usaçúcar & $\begin{array}{c}\text { Alto } \\
\text { Alegre }\end{array}$ & \begin{tabular}{c} 
Coruripe \\
\hline Unidades
\end{tabular} \\
\hline Funcionários & 24 & 06 & 11 & 08 & 04 & 10 & 04 & 06 \\
\hline $\begin{array}{l}\text { Área agrícola cultivada } \\
\text { (mil ha) }\end{array}$ & 860 & 450 & 346 & - & 168 & 18,3 & 173,3 & - \\
\hline Colheita mecanizada (\%) & 98 & 100 & 96,9 & 98 & 99,2 & - & - & - \\
\hline Moagem (milhões t) & 62,7 & 29,3 & 31 & 23 & 20 & 18,1 & 9,46 & 14,18 \\
\hline $\begin{array}{l}\text { Produção de açúcar } \\
\text { (milhões t) }\end{array}$ & 4,5 & 0,455 & 2,5 & 1,5 & 1,23 & 1,78 & 0,86 & 0,019 \\
\hline $\begin{array}{l}\text { Produção anual de } \\
\text { etanol (bilhões L) }\end{array}$ & 2,1 & 2,123 & 1,6 & 0,79 & 0,751 & 0,431 & 0,23 & 0,48 \\
\hline $\begin{array}{l}\text { Cogeração de energia } \\
\text { (MW) }\end{array}$ & 940 & 2100 & 1.346 & 1.082 & 741 & 703,05 & 609,02 & 608,16 \\
\hline
\end{tabular}

Fonte: As autoras - adaptado de Relatórios de Sustentabilidade das Empresas, 2017

De acordo com os dados do Quadro 1, a moagem dos grupos avaliados atingiu 207,74 milhões de t, o que representou $31,2 \%$ das 665,59 milhões de t de cana-de-açúcar produzida no Brasil em 2015/16 segundo dados da CONAB (2017). O grupo Raízen, com suas 24 unidades e 32,88\% do total de unidades analisadas, apresentou valores $102,26 \%$ superior a segunda colocada, a empresa Biosev.

Quanto a produção de açúcar e de etanol (Quadro 1), os grupos estudados alcançaram 12,844 milhões de t e 8,505 bilhões de L, o que representou 38,3\% e 27,9\%, respectivamente do total produzido no país em 2015/16 (CONAB, 2017), o que demonstra a concentração deste mercado. 


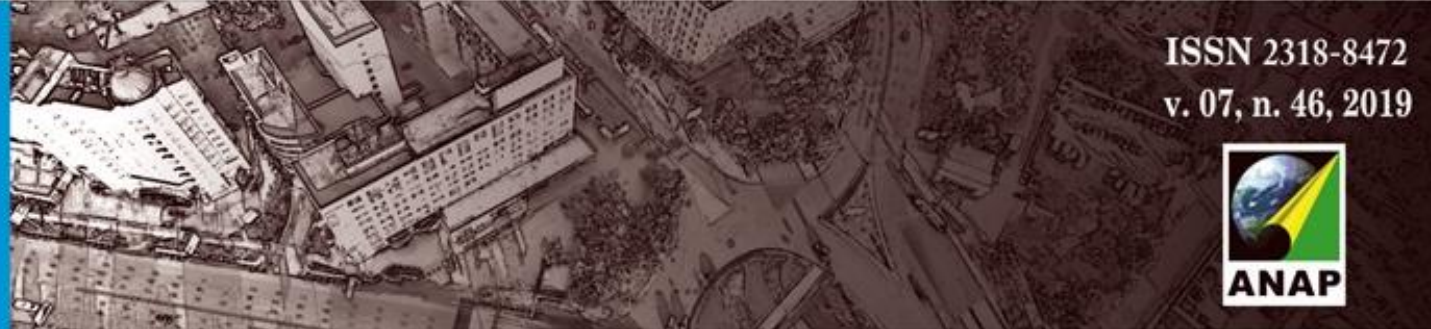

Revista Nacional de

Gerenciamento de Cidades

Há empresas que se destacam na produção de açúcar, enquanto outras, na de etanol, sendo a decisão de produzir açúcar ou etanol independente da demanda e dos preços dos produtos à época da colheita. A dependência está mais relacionada às oportunidades de tradings e da formação de estoque a custos consideráveis, já que esses são os aspectos relevantes que marcam essa economia em todo o mundo, além dos sinais de preços e margens de comercialização nos respectivos mercados. $O$ etanol, por exemplo, tem seu preço determinado a partir de custos e das margens de distribuição, com a indústria e a agricultura se destacando como os maiores tomadores de preços. Outro fator é que a distribuição e a revenda do produto final estão diretamente ancoradas no setor de petróleo e derivados. Com solo fértil e clima propício para o cultivo da cana-de-açúcar, o Brasil demonstra sua expertise no mercado de açúcar, detendo, hoje, 45\% das exportações mundiais (BATISTA, 2017).

Correlacionando a Tabela 1 e o Quadro 1, é possível verificar que há a utilização do bagaço da cana-de-açúcar em todos os grupos analisados. O processo de cogeração de energia com a queima do bagaço, resíduo da produção do açúcar e do etanol, possibilita a auto sustentação da empresa, minimiza custos, além de gerar receitas não operacionais com a venda do excedente, fruto em tese de um Sistema de Gerenciamento Ambiental atrelado a ABNT NBR ISO 14001, que trabalha a correta destinação dos resíduos dos processos. Especificamente no caso das usinas sucroenergéticas, outros produtos podem ser gerados com o uso dos resíduos, como por exemplo: adubo (com a utilização de vinhaça, torta de filtro, cinza e fuligem); forragem para alimentação animal, fibrocimento e concreto, substituição por areia em construções, papel; madeira, etanol de 2 a geração, cosméticos, substrato para hidroponia e bioplástico, todos a partir do uso do bagaço da cana-de-açúcar.

Na safra 2015/16, a produção do bagaço foi de 166,40 milhões de t no país e a sua queima foi responsável por 6,8295\% da matriz energética brasileira em 2017, considerando-se 399 usinas e uma capacidade instalada de 10.909.920 KW (RAMOS; NACHILK, 2017).

Dentre as empresas avaliadas, aquela que possui a maior capacidade produtiva de cogeração de energia é a Odebrechet com 2100 MW e segundo o relatório de sustentabilidade da Raízen, a comercialização anual de energia pelo grupo é suficiente para suprir uma cidade de 5 milhões de habitantes, o que denota a importância de tal processo.

A análise possibilita ainda verificar que as usinas têm papel fundamental no desenvolvimento econômico do Brasil, atingindo conjuntamente a geração de 124.656 empregos diretos, em 73 unidades. Há que se destacar que algumas possuem unidades fora do país, contudo, neste estudo, somente as unidades produtoras de açúcar e etanol proveniente da cana-de-açúcar como matéria prima foram consideradas, não sendo avaliadas empresas como a Guarani, do grupo Tereos, que possui 49 unidades industriais, em 13 países distintos, mas utilizando além da cana-de-açúcar, o milho, a mandioca, a beterraba, o trigo, a batata e a alfafa.

Três grupos analisados, Usaçucar, Alto Alegre e Coruripe, não apresentam em seu relatório o porcentual de colheita mecanizada de seus processos, contudo, os demais possuem atualmente uma média de $98,42 \%$, com destaque para a empresa Odebrechet com porcentual de $100 \%$. Tal 


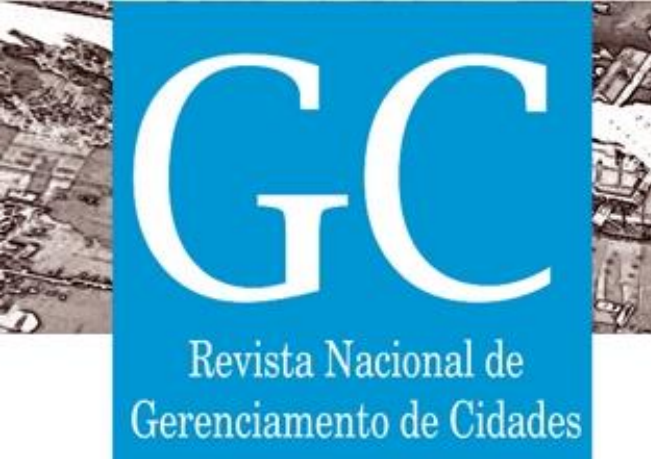

fato é derivado da pressão legal, ambiental e social contra a queima da cana-de-açúcar, a qual inviabiliza o processo de colheita manual. Em 19/09/2002 foi promulgada a Lei Estadual № 11.241, regulamentada pelo Decreto 47.700 de 11/03/2003, que estabeleceu um cronograma de eliminação da queima como forma de despalhamento da cana-de-açúcar para fins de colheita no Estado de São Paulo para 2021 em áreas mecanizáveis e 2031 em áreas não mecanizáveis, com declividade superior a $12 \%$ e/ou menores que 150 ha com estrutura de solo que inviabilizem a adoção de técnicas usuais de mecanização da atividade de corte de cana (SÃO PAULO, 2002; SÃO PAULO, 2003). Em 2018, a média brasileira referente ao sistema de colheita da cana mecanizada representou $91 \%$ do total (CONAB, 2018).

Em 2007 foi assinado um acordo de intenções firmado pelo Governo do Estado de São Paulo e denominado de Protocolo Agroambiental do Setor Sucroenergético, com o objetivo, principal, de antecipar o cronograma de eliminar o uso do fogo na colheita manual da cana-de-açúcar. A adesão ao acordo foi feita de forma voluntária, sendo participantes as usinas signatárias, representadas por sua instituição patronal a União da Indústria de Cana-de-açúcar (UNICA) e o Governo Estadual por intermédio da Secretaria de Agricultura e Abastecimento e Secretaria de Meio Ambiente (PROTOCOLO, 2017).

O Protocolo Agroambiental do Setor Sucroenergético, representou um acordo pioneiro, que entre outras disposições determinou: (i) a antecipação dos prazos legais para o fim da despalha da cana por meio do uso de fogo para 2014 (nas áreas mecanizáveis, para todas as unidades industriais signatárias) e 2017 (áreas não mecanizáveis) e (ii) a recuperação de matas em nascentes e a proteção das áreas de preservação de outros cursos d'água (PROTOCOLO, 2017). Assim, desde o início de 2018 estão totalmente proibidas a queima de palha para a colheita da cana-de-açúcar no Estado de São Paulo.

Quanto a questão ambiental, é possível verificar um posicionamento favorável de todos os grupos, fruto das pressões sociais e legais. Para o aumento de seu Market Share e a conquista de mercados globais, as empresas investem veemente em qualidade, mais especificamente em qualidade de normalização, e que contempla segundo Oakland (1994) e Shiba, Graham e Walden (1997), a certificação da qualidade.

Neste aspecto, buscando-se compreender a vertente da qualidade trabalhada e a amplitude de certificações que os grupos apresentam, foi realizado um levantamento, verificando aquelas que são sinérgicas e ou específicas a cada empreendimento, sendo seus dados apresentados na Quadro 2. 


\section{Revista Nacional de}

Gerenciamento de Cidades

Quadro 2: Certificações apresentadas por grupos sucroenergéticos brasileiros, 2015/16

\begin{tabular}{|l|c|c|c|c|c|c|c|c|}
\hline Certificações & Raízen & Odebrecht & Biosev & Guarani & $\begin{array}{c}\text { São } \\
\text { Martinho }\end{array}$ & $\begin{array}{c}\text { Usa } \\
\text { çucar }\end{array}$ & $\begin{array}{c}\text { Alto } \\
\text { Alegre }\end{array}$ & Coruripe \\
\hline Bonsucro & $\mathrm{X}$ & $\mathrm{X}$ & $\mathrm{X}$ & $\mathrm{X}$ & $\mathrm{X}$ & & $\mathrm{X}$ & \\
\hline CARB & $\mathrm{X}$ & $\mathrm{X}$ & $\mathrm{X}$ & & & $\mathrm{X}$ & $\mathrm{X}$ & \\
\hline EPA & $\mathrm{X}$ & & $\mathrm{X}$ & & & $\mathrm{X}$ & $\mathrm{X}$ & \\
\hline Etanol Verde & $\mathrm{X}$ & $\mathrm{X}$ & $\mathrm{X}$ & $\mathrm{X}$ & $\mathrm{X}$ & & $\mathrm{X}$ & \\
\hline FSSC 22000 & $\mathrm{X}$ & & $\mathrm{X}$ & $\mathrm{X}$ & & & $\mathrm{X}$ & $\mathrm{X}$ \\
\hline $\begin{array}{l}\text { Greenergy Bioethanol } \\
\text { Sustainability } \\
\text { Programme }\end{array}$ & & & & & $\mathrm{X}$ & & & \\
\hline Halal & & & & & & & & \\
\hline ISCC & $\mathrm{X}$ & & & $\mathrm{X}$ & $\mathrm{X}$ & & $\mathrm{X}$ & \\
\hline $\begin{array}{l}\text { ABNT NBR ISO } \\
\text { 22000:2005 }\end{array}$ & $\mathrm{X}$ & & & & & & & \\
\hline Kosher & & & $\mathrm{X}$ & $\mathrm{X}$ & & & & \\
\hline Lab2025 & $\mathrm{X}$ & & $\mathrm{X}$ & $\mathrm{X}$ & & & $\mathrm{X}$ & \\
\hline ABNT NBR ISO 14001 & $\mathrm{X}$ & & $\mathrm{X}$ & & & & & \\
\hline $\begin{array}{l}\text { ABNT NBR ISO } \\
\text { 14725:2014 }\end{array}$ & & & $\mathrm{X}$ & & & & & \\
\hline $\begin{array}{l}\text { ABNT NBR ISO } \\
\text { 17025:2005 }\end{array}$ & & & $\mathrm{X}$ & & $\mathrm{X}$ & & & \\
\hline $\begin{array}{l}\text { ABNT NBR ISO } \\
\text { 9001:2008 }\end{array}$ & $\mathrm{X}$ & & $\mathrm{X}$ & $\mathrm{X}$ & $\mathrm{X}$ & & $\mathrm{X}$ & $\mathrm{X}$ \\
\hline NSF & & & & $\mathrm{X}$ & & & & \\
\hline OHSAS 18001 & & & $\mathrm{X}$ & & & & & \\
\hline RFS2 & & & $\mathrm{X}$ & $\mathrm{X}$ & $\mathrm{X}$ & & & \\
\hline RTFO & & & & & & & \\
\hline Selo Energia Verde & $\mathrm{X}$ & & & & & & \\
\hline Prêmio Top Etanol & & & & & & & \\
\hline
\end{tabular}

Fonte: As autoras, 2017

De acordo com o Quadro 2,75\% dos grupos avaliados possuem certificação ABNT NBR ISO 9001:2008, Bonsucro e Etanol Verde; 62,5\% FSSC 2200 e CARB; 50\% EPA, ABNT NBR ISO 14001, Kosher, Halal e Selo Energia Verde; 25\% OHSAS 18001, ABNT NBR ISO 22000:2005, ABNT NBR ISO 17025:2005 e RFS2 e 12,5\% ABNT NBR ISO 14725:2014, NSF, Lab2025, ISCC, RTFO, Greenergy Bioethanol Sustainability Programme e Top Etanol.

Observa-se que os grupos investem em certificações da qualidade, algumas genéricas para empreendimentos que buscam a certificação da qualidade, como por exemplo a ABNT NBR ISO 9001:2008, presente em seis das oito empresas analisadas (Raízen, Biosev, Guarani, São Martinho, Alto Alegre e Coruripe) e que possibilita um Sistema de Gerenciamento da Qualidade e a ABNT NBR ISO 14001, adotada em metade dos grupos com o objetivo de criar um Sistema de Gerenciamento Ambiental que trata da qualidade na Supply Chain Management (Raízen, Guarani, São Martinho e Coruripe).

No caso específico da ABNT NBR ISO 9001:2008, ela define os requisitos mínimos para um sistema de gestão da qualidade, onde uma organização precisa demonstrar sua capacidade para fornecer produtos que atendam às necessidades do cliente e os requisitos regulamentares aplicáveis, de forma a aumentar a satisfação do cliente. Já a ABNT NBR ISO 14000 é uma ferramenta criada para auxiliar empresas a identificar, priorizar e gerenciar seus riscos 



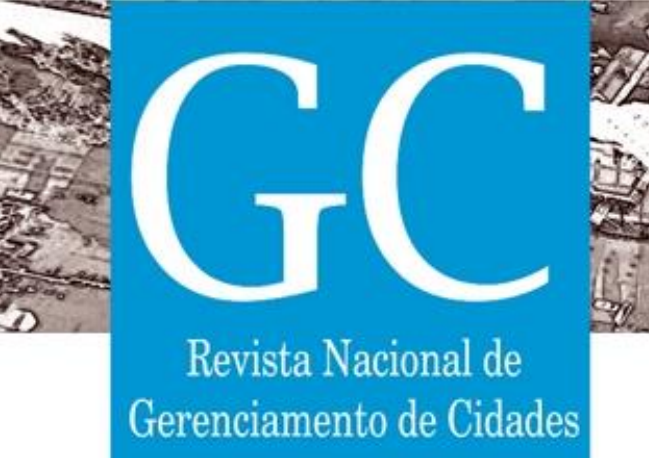

Além dessas, existem iniciativas próprias de empresas para assegurar a qualidade de laboratórios, como o Lab2025 do grupo Biosev, que busca o aprimoramento das informações, documentações e procedimentos gerados nos laboratórios da empresa, visando a garantia da máxima qualidade. Criado pela equipe da qualidade da empresa, o Lab2025 leva em consideração os requisitos do Sistema de Gestão de Laboratórios definidos na norma ABNT NBR ISO/IEC 17025.

A certificação OHSAS 18001 (Occupational Health and Safety Assessments Series) apresentada pelos grupos Raízen e Coruripe, é uma norma de Sistema de Gestão de Segurança e Saúde Ocupacional (SGSSO) que visa proteger e assegurar que os colaboradores de uma organização tenham um ambiente de trabalho saudável e seguro.

As certificações Kosher e Halal, que respectivamente possibilitam a certificação para a comercialização de produtos para a dieta judaica ortodoxa e islâmica, são apresentadas pelas empresas Raízen, Biosev, Guarani, Alto Alegre e São Martinho, sendo que a Kosher está presente nas quatro primeiras empresas, enquanto a Halal apenas não é apresentada na Biosev.

Para a certificação Kosher, inicialmente, uma pesquisa minuciosa é realizada para levantamento de dados sobre os ingredientes que compõem os produtos (componentes, fluxograma e lista de fornecedores), bem como o processo de fabricação empregado (sistema de caldeiras, vapor, planta da fábrica e etc). Numa segunda etapa, após ter sido constatado que o produto (ou produtos) em questão preenchem as normas da dieta casher, é agendada uma visita de um rabino ortodoxo à fábrica, para que o produto possa ser aprovado. Sem a avaliação de um rabino ortodoxo, perito neste assunto, um Certificado Kosher jamais poderá ser emitido.

Atualmente a população islâmica no mundo situa-se em torno de 1,6 bilhão de habitantes, correspondentes a cerca de $22 \%$ da população mundial. De acordo estudos realizados pelo $P e w$ Research Center estima-se que será a religião com maior crescimento nas próximas quatro décadas, devendo atingir cerca 2,8 bilhões fiéis em 2050 e cerca $30 \%$ da população mundial. Portanto, trata-se de um vasto mercado a ser conquistado e certificação Halal agrega ao produto vantagens competitivas tanto no curto como no longo prazo, considerando-se o crescimento projetado do referido mercado (APRENDENDO A EXPORTAR, 2017).

Neste estudo, a certificação NSF (National Sanitation Foundation) está presente apenas no grupo Guarani. A NFS é um dos mais respeitado certificados do mundo para a segurança alimentar com o foco em alimentos, água, ar em recintos fechados e meio ambiente. A NSF realiza testes a produtos e análise de materiais por meio de inspeções em fábricas sem aviso prévio. Cada aspecto do desenvolvimento de um produto é cuidadosamente avaliado antes de este obter a certificação.

As demais iniciativas de certificações são específicas ao segmento sucroenergético, e neste contexto destaca-se a Bonsucro, que segundo Vicente (2012) é uma certificação global lançada em julho de 2011 que avalia a sustentabilidade dos produtos fabricados a partir da cana e é atualmente o modelo mais utilizado no Brasil. A Bonsucro está presente em seis dos oito grupos pesquisados (Raízen, Odebrecht, Biosev, Guarani, São Martinho e Alto Alegre), sendo um selo 


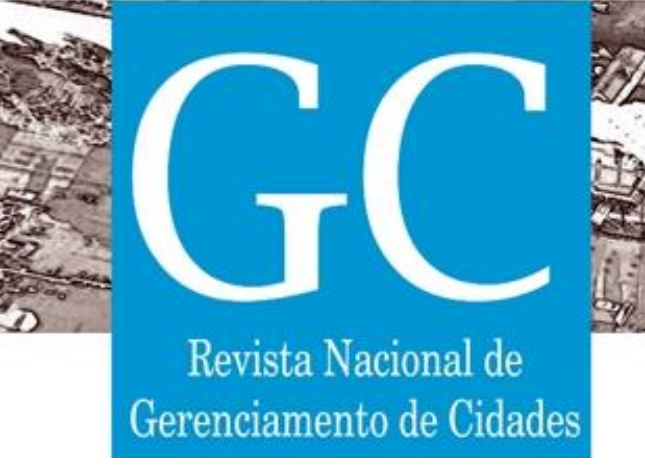

essencial para a atuação em mercados internacionais, ou seja, para exportação. As empresas certificadas pela Bonsucro têm atestadas as condições sustentáveis em que seus produtos são fabricados, tornando-os aptos para a comercialização em países integrantes da União Europeia (UE).

Em 2016, das 56 unidades produtoras de cana-de-açúcar e produtos derivados certificadas no mundo pela Bonsucro, 43 são empresas brasileiras (UNICA, 2016). Segundo informações da Bonsucro, que reúne organizações não-governamentais como a WWF (World Wide Fund for Nature) e companhias como Cargill, Shell e Coca-Cola, em 2012, 2,04\% da cana cultivada em todo o mundo recebeu o selo de certificação da entidade, que tem sede em Londres. Isso equivale à produção de 30,5 milhões de t de cana-de-açúcar, que ao ser processada pode ser convertida em 2,2 milhões de t de açúcar e 1,6 milhões de L de etanol por ano (UNICA, 2012a). As demais certificações são específicas para empresas que comercializam combustível e energia. A certificação EPA (Environmental Protection Agency), presente nos grupos Raízen, Biosev, Usaçucar e Alto Alegre, é um registro exigido para qualquer empresa que deseja exportar etanol para os Estados Unidos, e que atesta que o combustível cumpre todos os requisitos ligados a redução de emissão de gases de efeito estufa.

Buscando atingir os mais altos padrões de sustentabilidade, unidades da Raízen já aprovadas no EPA, além de outras dos grupos Biosev, Usaçucar e Alto Alegre também obtiveram o registro no CARB (California Air Resources Board). O selo possibilita que as unidades estejam aptas a exportar etanol de acordo com o Padrão de Combustível de Baixo Carbono (Low Carbon Fuel Standard, ou LCFS), normatização adotada na Califórnia, estado americano conhecido por seguir avançadas e rígidas regras ambientais.

A certificação RFS2 (Renewable Fuel Standard 2), presente nos grupos Biosev e Usaçucar, é uma exigência para exportar o álcool como biocombustível para os EUA, e que garante a capacidade de redução de emissões de gases de efeito estufa em pelo menos $50 \%$ em comparação à gasolina.

A certificação ISCC (International Sustainability Carbon Certification), apresentada pelo grupo Raízen, assegura conformidade com parâmetros da União Europeia para a produção sustentável na Diretriz da Energia Renovável (RED) (EU-RL 2009/28/EC), certificando inclusive o etanol de segunda geração.

A Obrigação de Combustíveis Renováveis para Transporte do Reino Unido (Renewable Transport Fuel Obligation - RTFO), certificação apresentada pelo grupo São Martinho, foi desenvolvida pelo departamento nacional de transporte do Reino Unido e administrado pela Agência Britânica de Combustíveis Renováveis (Renewable Fuels Agency, RFA), e visa reduzir as emissões de carbono no segmento de transporte, atualmente responsável por quase $25 \%$ das emissões do país. Para tanto, estipula que uma porcentagem específica de "combustíveis de estrada" tenha origem em fontes renováveis de combustível. Concomitantemente ao mandato de mistura, o programa estabelece critérios de sustentabilidade (RTFO meta-standards) para os biocombustíveis, cujo escopo agrega sete principais temas: cinco ambientais e dois sociais, cabendo aos agentes 


